\title{
Actinorhizal plants of Turkey: formation of nodules, cluster roots and ectomycorrhizal roots
}

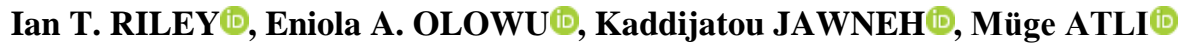 \\ Department of Plant Production and Technologies, Faculty of Agricultural Science and Technologies, Nigde Omer Halisdemir University, Nigde, \\ 51240, Turkey \\ Corresponding author: I. T. Riley, e-mail: ian@riley.asia \\ Author(s) e-mail: eniolowu@gmail.com, kjawneh@gmail.com, mugeatli51@gmail.com
}

\section{ARTICLE INFO}

Received: July 20, 2021

Received in revised form: July 27,2021

Accepted: November 12, 2021

\section{Keywords:}

Actinorhizae

Ectomycorrhizae

Nodulation

Proteiod roots

\begin{abstract}
None of the known native actinorhizal species in Turkey, Alnus glutinosa and A. orientalis (Betulaceae), Datisca cannabina (Datiscaceae), Elaeagnus angustifolia and Hippophae rhamnoides (Elaeagnaceae), and the widely-planted exotic Casuarina cunninghamiana (Casuarinaceae), have confirmed records of actinorhizae in Turkey. This study determined the capacity of representative actinorhizal plants in Turkey to form nodules, cluster roots and ectomycorrhizal roots in a typical central Anatolian soil with and without amendment of soil and nodule extracts, as well as in soil from Adana and Izmir. Nodulation was confirmed experimentally for E. angustifolia and C. cunninghamiana in Niğde soil (the latter only with addition Adana or Izmir soil), but only observationally for A. glutinosa during sample collection in Rize. Cluster roots developed strongly in C. cunninghamiana, and likewise ectomycorrhizal roots in Allocasuarina verticillata (included as a reference species) but only to a lesser extent in $C$. cunninghamiana. The nodulation status of the natives, D. cannabina and $H$. rhamnoides, remains to be investigated.
\end{abstract}

\section{Introduction}

Actinorhizal plants with nitrogen-fixing nodules induced by species of the Actinobacteria, Frankia, are important endemics and economic exotics in many climatic and floristic regions worldwide. Actinorhizal species are found in 24 genera in eight families (Benson and Silvester 1993), however, when these species are reported in specific locations there is often an untested assumption that they are actinorhizal and will be nodulated and fixing nitrogen. However, this can be an invalid assumption, for example, Paschke (1997) makes the point that for Dryas (Rosaceae), although widespread in Europe and the USA, there were no confirmed reports of nodulation throughout that range at the time of writing. Also, his review of 80 actinorhizal species in the western USA did not cite evidence for nodulation of any of these species. Markham (2009) addressed this issue experimentally and was unable to confirm that Dryas integrifolia can nodulate in response to inoculation with several Frankia strains. Markham attributed this apparent inconsistency to there being non-nodulating species in otherwise actinorhizal genera, but lack of nodulation in other contexts could also be a result of non-conducive conditions or absence of compatible Frankia.

Turkey is a regarded as having high floristic richness (Kier et al. 2005) with nearly two thirds of the country in Mediterranean or Mediterranean-influenced continental climate zones with these areas possessing rich floras. However, unlike, for example, Australia with $>60$ putative actinorhizal species in the Casuarinaceae (Riley 2021) and 80 species in varies families in the western USA (Paschke 1997), the number of actinorhizal species in Turkey is low and their nodulation status undetermined. There are five known native actinorhizal species in Turkey, Alnus glutinosa and A. orientalis (Betulaceae), Datisca cannabina (Datiscaceae), Elaeagnus angustifolia and Hippophae rhamnoides (Elaeagnaceae). Casuarina cunninghamiana (Casuarinaceae) is the only introduced actinorhizal species and is widely used as an ornamental, landscape and windbreak tree in provinces along the Mediterranean and Aegean coasts (Riley and Korkmaz 2019). Although, E. angustifolia and $H$. rhamnoides are widely distributed species that produce edible fruit, their current horticultural use in Turkey is minimal.

Although there is no direct evidence of nodulation of actinorhizal plants in Turkey, the authors of a molecular study of Frankia report collecting nodules from $A$. orientalis at two sites in Turkey (Ormancık, Adana Province and Demirtaş, Antalya Province) (supplementary data in Põlme et al. 2014). There is no similar incidental information available for other native species, and given that nodulation of Casuarina grown outside its natural range does not occur unless compatible Frankia are also introduced (Simonet et al. 1999), it should not be assumed that C. cunninghamiana is nodulated in Turkey.

With actinorhizal species having great potential for agroecosystem restoration and improvement in contexts with infertile or degraded soil (e.g. Roy et al. 2011), and as pioneer species in assisted secessional restoration (e.g. Parrotta 1999), it is important that their nodulation status/potential is determined in target contexts. Therefore, the aim of this study was to determine 
the capacity of representative actinorhizal plants in Turkey to nodulate in a typical central Anatolian soil with and without amendment of soil and nodule extracts (that could supply compatible Frankia). In addition, root responses such as formation of cluster roots and ectomycorrhizal associations were assessed. The data obtained provides the first evidence of nodulation of the test species (A. glutinosa, C. cunninghamiana and $E$. angustifolia) both experimentally and observationally (during sampling for materials used as experimental amendments) in Turkey.

\section{Materials and Methods}

Seeds were sourced from Australia and Turkey as detailed in Table 1. Seeds of A. glutinosa and depulped E. angustifolia were stratified in moist sand at $5^{\circ} \mathrm{C}$ for at least 6 weeks to promote germination. Soil ( $<200 \mathrm{~mm}$ deep) and nodules were variously obtained from the root zones of actinorhizal species as detailed in Table 1. Basic analysis of the soil was performed by the Niğde government soil laboratory (TC Niğde İl Özel İdaresi Toprak ve Su Analiz Laboratuvarı, Niğde, Turkey) as shown in Table 2. In addition, during the collection of soil samples, exposed roots were examined for the presence of nodules, and the roots systems of mechanically uprooted mature E. angustifolia trees in Niğde were likewise examined for nodules.

Plants were grown in mixtures of soil and peat (Emin Torf, Yeniçağa, Bolu Province, Turkey) in plastic pots in a greenhouse as detailed below for all experiments. The addition of field soil (either directly or as an aqueous suspension) was used as a potential source of Frankia in the experiments. In the final two experiments, suspensions of nodules of $A$. verticillata (Table 1) were also included as an inoculum.

The amendments of soil and nodule suspensions were prepared as follows. Air-dried soil $(100 \mathrm{~mL})$ from Adana, Niğde and Rize were separately suspended in $100 \mathrm{~mL}$ tap water, vigorously shaken for 5-10 $\mathrm{min}$ and allowed to settle. The supernatants were decanted and applied as an inoculum in the first and second experiments. Air-dried nodules ( $0.5 \mathrm{~g}$ air dried) from A. verticillata were crushed in $50 \mathrm{~mL}$ of skimmed milk and applied $(1 \mathrm{~mL}$ per plant) as an inoculum in the final two experiments.

Table 1. Seed, soil and nodule sources used in greenhouse experiments to assess the formation of nodules, cluster roots and mycorrhizal roots in actinorhizal plants in Turkey.

\begin{tabular}{|c|c|c|c|}
\hline Material & $\begin{array}{l}\text { Actinorhizal species or } \\
\text { associated species }\end{array}$ & Collection details & Expt \\
\hline \multirow[t]{4}{*}{ Seed } & Allocasuarina verticillata & $\begin{array}{l}\text { 26.I.2019, Linden Park, SA, Australia, } 34^{\circ} 56^{\prime} 23^{\prime \prime} \text { S, } 138^{\circ} 38^{\prime} 34^{\prime \prime} \text { E, planted, public garden, } \\
\text { collected by IT Riley }\end{array}$ & $1,2,3,4,5$ \\
\hline & $\begin{array}{l}\text { Casuarina } \\
\text { cunninghamiana }\end{array}$ & $\begin{array}{l}\text { 27.X. } 2018 \text {, Antalya, Antalya, Turkey, } 36^{\circ} 53^{\prime} 06^{\prime \prime} \mathrm{N}, 30^{\circ} 40^{\prime} 54^{\prime \prime} \mathrm{E} \text {, planted, public garden, } \\
\text { collected by IT Riley }\end{array}$ & $1,2,3,4,5$ \\
\hline & Elaeagnus angustifolia & $\begin{array}{l}\text { 2.X.2018, Niğde Ömer Halisdemir University, Niğde, Turkey, } 37^{\circ} 56^{\prime} 17.5^{\prime \prime} \mathrm{N}, 34^{\circ} 37^{\prime} 34.4^{\prime \prime} \\
\text { E, planted/volunteer, collected by M Altı and IT Riley, stratified before planting }\end{array}$ & 1,2 \\
\hline & Alnus glutinosa & $\begin{array}{l}\text { X.2018, Ordu, Turkey, } 40^{\circ} 58^{\prime} 34^{\prime \prime} \text { N, } 37^{\circ} 58^{\prime} 03^{\prime \prime} \text { E, natural stand (exact location unknown), } \\
\text { collected by E Ekbiç }\end{array}$ & 1,2 \\
\hline \multirow[t]{4}{*}{ Soil } & C. cunninghamiana & 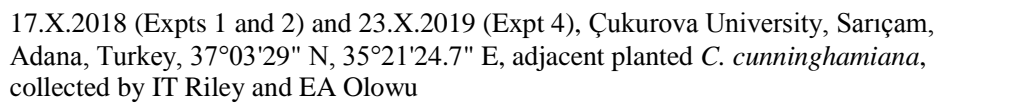 & $1,2,4$ \\
\hline & & $\begin{array}{l}\text { 17.I.2020, Ege University, Erzene, Bornova, Izmir, Turkey, } 38^{\circ} 27^{\prime} 19^{\prime \prime} \text { N, } 27^{\circ} 13^{\prime} 34^{\prime \prime} \text { E, } \\
\text { adjacent planted } \text { C. cunninghamiana, collected by IT Riley }\end{array}$ & 5 \\
\hline & E. angustifolia & $\begin{array}{l}\text { Various dates, Niğde Ömer Halisdemir University Campus, Niğde, Turkey, in fields, } \\
37^{\circ} 56^{\prime} 17.5^{\prime \prime} \mathrm{N}, 34^{\circ} 37^{\prime} 34.4^{\prime \prime} \mathrm{E} \text {, with E. angustifolia within } 100 \mathrm{~m} \text { radius, collected by the } \\
\text { authors }\end{array}$ & $1,2,3$ \\
\hline & A. glutinosa & $\begin{array}{l}\text { 22.VI.2018, Yaylaköy, Çamlıhemşin, Turkey, } 40^{\circ} 51^{\prime} 36^{\prime \prime} \mathrm{N}, 41^{\circ} 00^{\prime} 03^{\prime \prime} \mathrm{E} \text {, collected by IT } \\
\text { Riley }\end{array}$ & 1,2 \\
\hline Nodules & A. verticillata & $\begin{array}{l}\text { 25.VII.2019, Nepean Bay, Kangaroo Island, SA, Australia, } 35^{\circ} 44^{\prime} 14 " \text { " S } 137^{\circ} 35^{\prime} 57^{\prime \prime} \text { E, } \\
\text { trees uprooted by roadworks, collect by IT Riley, MH Ryder and JR Rathjen. }\end{array}$ & 4,5 \\
\hline
\end{tabular}

Table 2. Analysis of soils from three locations used in the growth medium to assess the formation of nodules, cluster roots and mycorrhizal roots in actinorhizal trees in Turkey.

\begin{tabular}{|c|c|c|c|c|c|c|c|c|c|}
\hline Location & Site & Associated actinorhizal species ${ }^{1}$ & Collection & $\begin{array}{c}\text { Saturation } \\
(\%)\end{array}$ & pH & $\begin{array}{l}\text { Salt } \\
(\%)\end{array}$ & $\begin{array}{c}\mathrm{CaCO}_{3} \\
(\%)\end{array}$ & $\begin{array}{c}\text { Olsens P } \\
(\mathbf{p p m})^{2}\end{array}$ & $\underset{(\mathbf{p p m})^{2}}{\mathbf{K}}$ \\
\hline Adana & Garden & Casuarina cunninghamiana & 23.X.2019 & 84 & 7.7 & 0.05 & 31 & 6.8 & 137 \\
\hline Izmir & Garden & C. cunninghamiana & 18.I.2020 & 57 & 7.9 & 0.04 & 17 & 5.8 & 127 \\
\hline Niğde & Field & Elaeagnus angustifolia & 11.IX.2020 & 45 & 7.5 & 0.03 & 26 & 4.4 & 192 \\
\hline
\end{tabular}

${ }^{1}$ Soil collected adjacent to the listed tree, except in Niğde, where specimens of the tree occurred within a 100-m radius of the soil collection site. ${ }^{2}$ Elemental not oxide. 
Five experiments were conducted in growth medium consisting of various combinations of soil and peat, with and without amendment, to assess root responses including nodulation, cluster root and ectomycorrhizal root development. The greenhouse $\left(37^{\circ} 56^{\prime} 38^{\prime \prime} \mathrm{N}, 34^{\circ} 37^{\prime} 51^{\prime \prime} \mathrm{E}\right)$ was located on the campus of Niğde Ömer Halisdemir University, Turkey, with automatic ventilation, evaporative coolers and shade-cloth for cooling in summer and central heating for winter, however, the temperature was not rigorously controlled.

Experiment 1: C. cunninghamiana was grown in a full factorial experiment with four inoculation treatments, and sterilised or unsterilised growth medium (75\% Niğde soil plus $25 \%$ peat) in a randomised complete block design (4 replicates). The inoculation treatments $(1 \mathrm{~mL}$ per plant) were the three soil suspensions as described above plus an uninoculated control. The sterilisation treatment was three cycles of autoclaving at $121^{\circ} \mathrm{C}$ for $60 \mathrm{~min}$ with at least $48 \mathrm{~h}$ between cycles. C. cunninghamiana seeds were germinated in peat and transplanted to the treatment pots (round plastic pots, $125 \times 95 \mathrm{~mm}$ ) on 5 November 2018 . Inoculation treatments were applied 7 days after transplanting. The plants were watered as needed and in a manner to minimise the risk of cross contamination. By early February, 10 weeks after planting, many plants were chlorotic, so a low rate of complete soluble fertiliser ( $5 \mathrm{~mL}$ of $8 \mathrm{~g} 4.5 \mathrm{~L}^{-1}$, Thrive Soluble Fertiliser, Yates, Clayton, Vic., Australia) was applied weekly (but with minimal visual response). Plants were harvested for assessment after 20 weeks.

Experiment 2: A. glutinosa, A. verticillata, $C$. cunninghamiana and $E$. angustifolia were grown in an unsterilised growth medium ( $25 \%$ Niğde soil plus $75 \%$ peat) inoculated with a combined suspension of Adana and Rize soil (prepared as described above). The plants were germinated in peat and single plants transplanted to each pot (round plastic pots, $165 \times 140 \mathrm{~mm}$ ) on 10 March 2019. Other details were the same as experiment 1 , although no fertilizer was applied. Plants were harvested for assessment after 52 weeks.

Experiment 3: A. glutinosa, A. verticillata, $C$. cunninghamiana and E. angustifolia were grown in the same growth medium as in experiment 2 but in larger pots (square plastic pots, $115 \times 183 \mathrm{~mm}$ ) with no inoculum. One to two plants per pot were transplanted to 20 replicate pots on 17 April 2019. Other details were the same as experiment 2. Plants were harvested for assessment after 47 weeks.

Experiment 4: A. verticillata and C. cunninghamiana were grown in a full factorial experiment with and without inoculation in unsterilised growth medium (25\% Adana soil plus $75 \%$ peat) in a randomised complete block design with five replicates. The inoculum ( $1 \mathrm{~mL} \mathrm{plant}^{-1}$ ) was A. verticillata nodule suspension as described above. Seeds of the plants were germinated directly in the growth medium (in the same pots as experiment 1) in a growth chamber $\left(\sim 25^{\circ} \mathrm{C}\right)$, sown on 20 December 2019 and transferred to the greenhouse on 22 January 2020. Inoculation was applied 35 days after germination. The plants were watered as needed and from below to minimise the risk of cross contamination. Plants were harvested for assessment after 31 weeks.

Experiment 5: A. verticillata and C. cunninghamiana were grown in full factorial experiment using Izmir soil (25\%) with four replicates but otherwise as in experiment 4 . The seeds were sown into pots in the growth chamber on 24 January 2020 and transferred to the greenhouse 28 February 2020. Inoculation was applied 35 days after germination. Plants were harvested for assessment after 26 weeks.

At harvest, plant height and visual health were recorded. Shoot colour was scored on a four-point scale with zero being uniformly chlorotic (yellow) through to three for fully green. The plants were removed from pots and gently washed. Roots were assessed for their length, visual health, and the presence of nodules, cluster roots and mycorrhizal roots. Root health was scored on a three-point scale with one being poorly developed through to three for healthy and well developed. Roots were examined under a stereomicroscope to count nodules and cluster roots, and to observe any other root responses. Ectomycorrhizal roots were scored as absent (-), present (+) or present at moderate to high density $(++)$.

Data processing, analysis and visualisation was performed with R (www.R-project.org). Analysis of variance was conducted on complete data sets, e.g. plant height, however, differences between plants species were not statistically meaningful and the analysis could not done in data sets with many zero values. Given that the key responses needed to meet the aims of the study were categorical in nature, exploratory statistics were (Tukey 1997) used, where appropriate.

\section{Results}

Across the five experiments, nodules, cluster roots and ectomycorrhizal roots were variously observed depending on the plant species, soil and amendments. The key results are presented below for each plant species.

\subsection{Alnus glutinosa}

In the experiments that include A. glutinosa (experiments 2 and 3), although it germinated readily, its growth was poor with leaves chlorotic turning necrotic, and plants dying before harvest. Although no experimental data was obtained on the nodulation of A. glutinosa in Turkish soils, in the field where the soil was collected, nodules were observed (Figure 1a) with many occurring on roots within the litter layer.

\subsection{Allocasuarina verticillata}

Allocasuarina verticillata, included in this study as a reference species not currently grown in Turkey, was included in all but the first experiment with no nodulation observed despite being inoculated with a presumptively compatible nodule suspension in experiments 4 and 5 . Nevertheless, the plants grew well in all cases, growing as well as, or better than, $C$. cunninghamiana (Table 3 and Figure $1 \mathrm{~g}, \mathrm{~h}$ ), with shoot scores of 3 in Adana and Izmir soil, but exhibited mild chlorosis in Niğde soil with shoot scores of 2.4. Their root systems appeared healthy and well developed (scored as 3 in all experiments), but were not highly branched. Cluster roots were uncommon within only a single cluster root found on four plants (two plants in experiment 3 and one each in experiments 4 and 5; Table 2). In contrast, ectomycorrhizal roots were present in abundance in all cases. These were short, thick, mostly unbranched roots, growing perpendicular to the main root often with some terminal swelling (Figure 1i) consistent with range in ectomycorrhizal root morphology described by Brundrett and Tedersoo (2020). This not only contrasted with their lack of nodules and rare cluster roots in this species, it also contrasted with the low numbers of ectomycorrhizal roots found on C. cunninghamiana, the only other test species to have evident ectomycorrhizal roots. 
Although no nodules were found in these experiments, they were obtained from uprooted trees in a natural stand in Australia (Figure 2), where they occurred at low density on relatively thick roots near the crown or the plants. Efforts to find them on smaller, surface roots surrounding undisturbed trees were unsuccessful.

\subsection{Casuarina cunninghamiana}

Casuarina cunninghamiana was included in all experiments with nodules, cluster roots and ectomycorrhizal roots developing variously across the experiments. In experiment 1 , the plants grew slowly with a moderate proportion of chlorotic
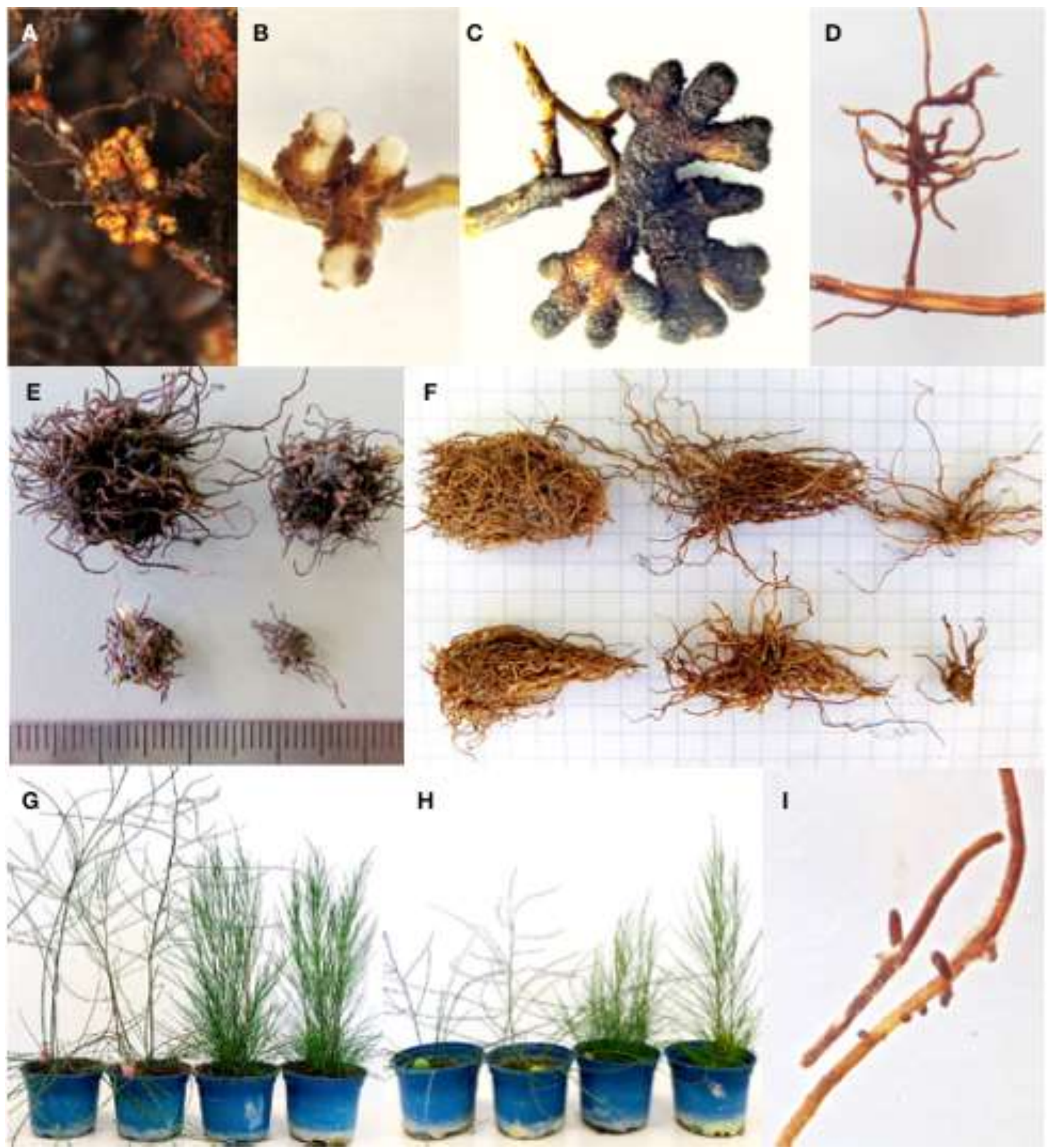

H
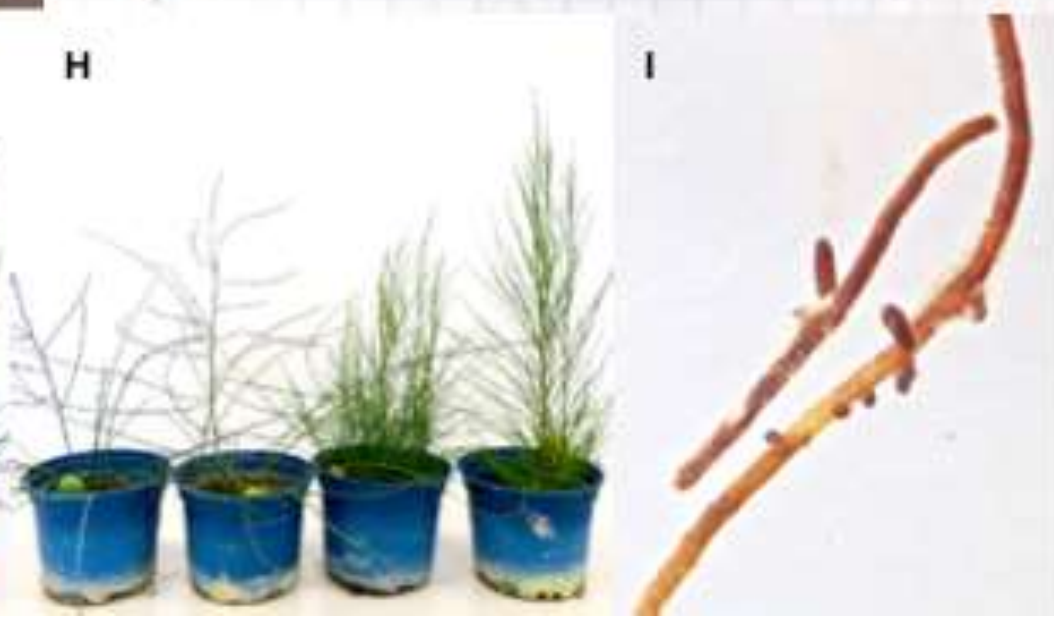

Figure 1. A. Frankia nodule (coralloid) on Alnus glutinosa growing naturally in Rize Province, Turkey; B, C, Frankia nodules, young unlobed and older lobed (coralloid) nodules, on Elaeagnus angustifolia container grown in $25 \%$ Niğde soil; D, cluster root in Casuarina cunninghamiana container grown in $25 \%$ Niğde soil; E, F, Frankia nodules with prolific development of nodules roots on C. cunninghamiana container grown in $75 \%$ Niğde soil for 1 year (Expt 2) and in $25 \%$ Adana soil for 7 months (Expt 4); G, H, growth of Allocasuarina verticillata and $C$. cunninghamiana in 25\% Adana soil after 7 months (Expt 4) and 25\% Izmir soil after 6 months (Expt 5); and I, mycorrhizal roots in $A$. verticillata that are short lateral roots that grow perpendicular to the main root often thicker with a terminal lobe (see in plants grown in $25 \%$ Niğde, Adana and Izmir soil, Epxts 3, 4 and 5, respectively). 


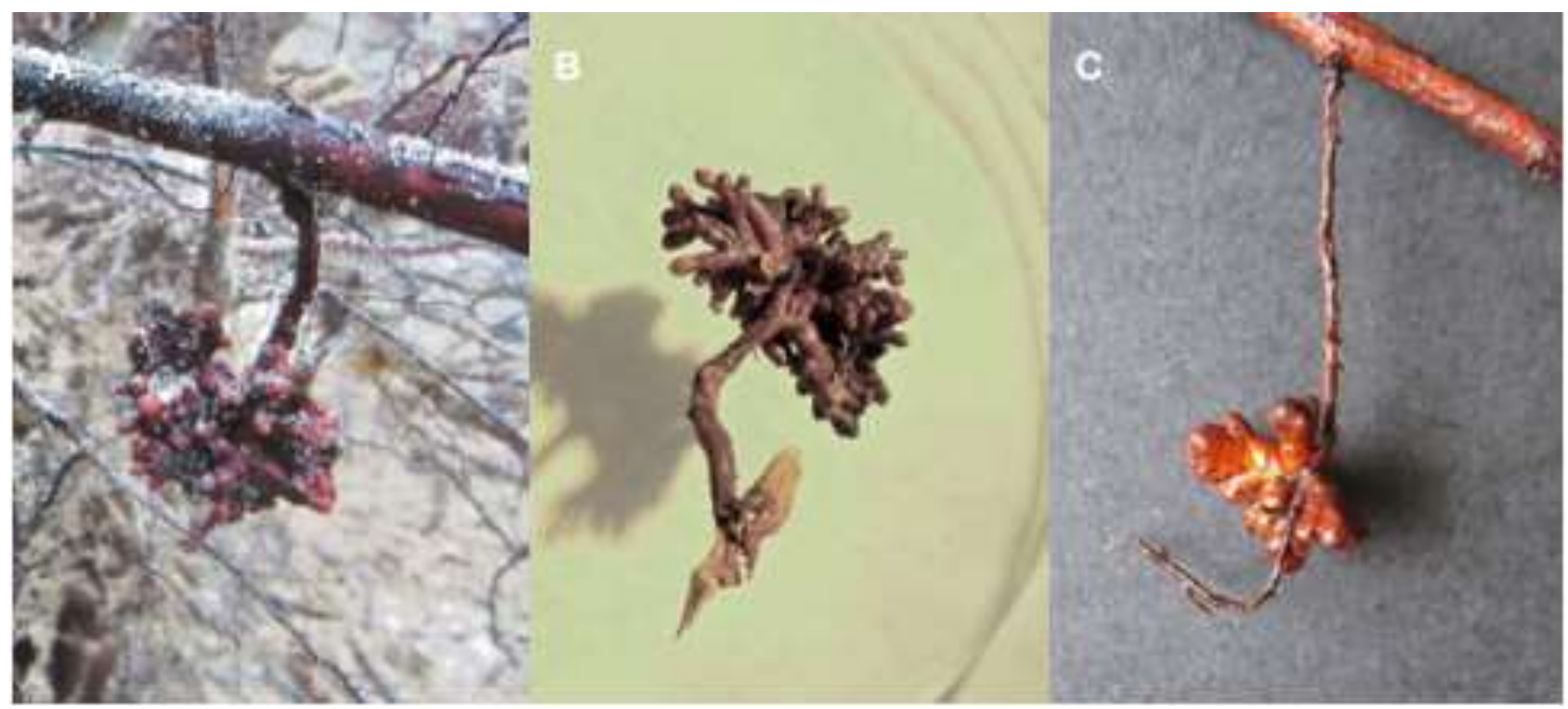

Figure 2. Frankia nodules (coralloid) on Allocasuarina verticillata from a natural stand at Nepean Bay, Kangaroo Island, SA, Australia. The tree was uprooted by roadworks, and nodules were found on short roots descending from larger lateral roots and less than $1 \mathrm{~m}$ from the crown of the tree. A and B are the same nodule, in situ in a light sandy soil and washed in the laboratory (about $50 \mathrm{~mm}$ across) and B is a younger, lobed but less branched nodule (about $20 \mathrm{~mm}$ across).

Table 3. Formation of nodules, cluster roots and ectomycorrhizal roots in actinorhizal plants, Allocasuarina verticillata (Ave), Casuarina cunninghamiana $(\mathrm{Ccu})$ and Elaeagnus angustifolia (Ean), in five greenhouse experiments using various growth medium and amendments. Growth medium included topsoils from Adana and Izmir, Turkey, adjacent to C. cunninghamiana, and Niğde, Turkey, adjacent to $E$. angustifolia, in 25 or $75 \%$ mixtures with peat (A25, I25 and N25/75, respectively) to ensure drainage in container grown plants. Amendments included supernatants of soil suspensions from soil collected adjacent to the three actinorhizal plants species, Alnus glutinosa (Agl-S, Rize, Turkey), C. cunninghamiana (Ccu-S, Adana) and E. angustifolia (Ean-S, Niğde), and a suspension A. verticillata nodules (Kangaroo Island, Australia) prepared by homogenising air-dried nodules in skimmed milk

\begin{tabular}{|c|c|c|c|c|c|c|c|c|c|c|}
\hline Expt & Species & Medium & Amendment & Reps & $\begin{array}{l}\text { Growth } \\
\text { (weeks) }\end{array}$ & $\begin{array}{l}\text { Plant height } \\
\quad(\mathrm{mm})\end{array}$ & $\begin{array}{l}\text { Shoot/root } \\
\text { score }\end{array}$ & Nodules $^{2}$ & $\begin{array}{l}\text { Cluster } \\
\text { roots }^{2}\end{array}$ & $\begin{array}{c}\text { Ectomycorrhizal } \\
\text { roots }^{3}\end{array}$ \\
\hline \multirow[t]{4}{*}{1} & $\mathrm{Ccu}$ & N75 & None & $10^{4}$ & 20 & 82 & $1.3 / 1.7$ & 0 & $9(9)$ & nd \\
\hline & $\mathrm{Ccu}$ & N75 & Agl-S & 10 & 20 & 73 & $1.8 / 2.0$ & 0 & $11(10)$ & nd \\
\hline & $\mathrm{Ccu}$ & N75 & Ccu-S & 10 & 20 & 70 & $1.3 / 2.0$ & 0 & $8(8)$ & nd \\
\hline & $\mathrm{Ccu}$ & N75 & Ean-S & 10 & 20 & 72 & $1.2 / 2.3$ & 0 & $15(8)$ & nd \\
\hline \multirow[t]{3}{*}{2} & Ave & $\mathrm{N} 25$ & $\mathrm{Agl} / \mathrm{Ccu}-\mathrm{S}$ & 5 & 52 & 499 & $2.4 / 3.0$ & 0 & $1(2)$ & ++ \\
\hline & $\mathrm{Ccu}$ & $\mathrm{N} 25$ & $\mathrm{Agl} / \mathrm{Ccu}-\mathrm{S}$ & 5 & 52 & 554 & $2.4 / 3.0$ & $2(4)$ & $1(2)$ & + \\
\hline & Ean & $\mathrm{N} 25$ & $\mathrm{Agl} / \mathrm{Ccu}-\mathrm{S}$ & 5 & 52 & 901 & $\mathrm{nd} / 2.8$ & $348(3)$ & $1(2)$ & - \\
\hline \multirow[t]{3}{*}{3} & Ave & $\mathrm{N} 25$ & None & 5 & 47 & 589 & $2.4 / 3.0$ & 0 & $1(1)$ & ++ \\
\hline & $\mathrm{Ccu}$ & $\mathrm{N} 25$ & None & 5 & 47 & 160 & $1.0 / 2.6$ & 0 & $57(5)$ & + \\
\hline & Ean & $\mathrm{N} 25$ & None & 5 & 47 & 611 & $\mathrm{nd} / 2.6$ & $56(5)$ & 0 & - \\
\hline \multirow[t]{4}{*}{4} & Ave & A 25 & None & 5 & 31 & 423 & $3.0 / 3.0$ & 0 & 0 & ++ \\
\hline & Ave & A25 & Ave-N & 5 & 31 & 471 & $3.0 / 3.0$ & 0 & 0 & ++ \\
\hline & $\mathrm{Ccu}$ & A 25 & None & 5 & 31 & 229 & $3.0 / 3.0$ & $1(2)$ & $14(5)$ & + \\
\hline & $\mathrm{Ccu}$ & A 25 & Ave-N & 5 & 31 & 289 & $3.0 / 3.0$ & $6(2)$ & $8(4)$ & + \\
\hline \multirow[t]{4}{*}{5} & Ave & $\mathrm{I} 25$ & None & 4 & 26 & 240 & $3.0 / 3.0$ & 0 & $1(1)$ & ++ \\
\hline & Ave & I 25 & Ave-N & 4 & 26 & 334 & $3.0 / 3.0$ & 0 & 0 & ++ \\
\hline & $\mathrm{Ccu}$ & $\mathrm{I} 25$ & None & 4 & 26 & 188 & $3.0 / 3.0$ & 0 & $7(4)$ & + \\
\hline & $\mathrm{Ccu}$ & $\mathrm{I} 25$ & Ave-N & 4 & 26 & 304 & $3.0 / 3.0$ & $8(2)$ & $2(2)$ & - \\
\hline
\end{tabular}

${ }^{1}$ Shoot/root scores are means on a four-point scale from zero for poor to three for healthy (see the text for details); E. angustifolia (Ean) shoots were not scored as the

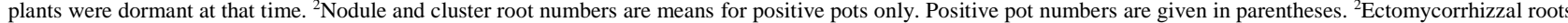
were scored as -, not present, + , present and ++, present at moderate to high density, with occurrence was consistent across replicates. ${ }^{3}$ Replicates in Expt 1 include 5 replicates each for sterile and non-sterile soil treatments that were combined given these treatments had no observable effect. nd, not determined. 
plants (overall shoot score of 1.5). This poor growth (Table 3) was attributed to the high proportion of Niğde soil which made for a heavy, hard-setting growth medium and the plants being grown over winter months with shorter day lengths even though the greenhouse was heated, consequently a greater proportion of peat was included in the subsequent experiments. (However, this was ineffective in Niğde soil, but growth and shoot scores were much better in experiments with Adana and Izmir soil). Although there was no nodulation in experiment 1 , the roots were generally well developed (overall score of 2) and much longer than the shoots (mean root-shoot ratio of 1.8). Cluster roots developed in 35 of the 40 pots with means per treatment ranging from 8 to 15 cluster roots per pot, with no statistically significant response to inoculation treatment. Ectomycorrhizal roots were not scored in experiment 1 .

Experiment 2, conducted in response to the lack of nodulation in experiment 1 , included a combined inoculum and unsterilised Niğde soil with more peat and growing period extending over a full year to maximise the probability of nodulation. In total, nine nodules (with air-dry weight ranging from 0.03 to $1.67 \mathrm{~g}$ and 6 to $25 \mathrm{~mm}$ long; a representative sample is shown in Figure 1e) developed with some in all $C$. cunninghamiana replicates ( 2 nodules pot $\left.^{-1}\right)$. The range from small to large with a highly branched, lobed structure and prolific nodule roots (Figure 1e) as described by Torrey (1976) and illustrated by Batista-Santos et al. (2015; their Figure 1 with zero salt treatment). However, cluster roots and ectomycorrhizal roots only occurred in small numbers (Table 3).

In the remaining experiments, nodulation of $C$. cunninghamiana nodulation occurred in plants grown in Adana and Izmir soil with and without inoculation (experiments 4 and 5), but not in Niğde soil (experiment 3). The mean nodule number ranged from one to eight per pot (Table 3 ) with air-dry weight ranging from 0.01 to $1.36 \mathrm{~g}$ and 4 to $15 \mathrm{~mm}$ long (a representative range of nodules are shown in Figure 1f) and, being younger nodules than in experiment 2, these were lighter in colour. Again, the nodules had abundant nodules roots. Although nodules occurred in inoculated treatments, the source of the Frankia is mostly likely to have been the field soil because inoculation failed to lead to nodulation of the homologous control (A. verticillata). No nodules were found on shallow roots of $C$. cunninghamiana exposed when sampling soils for these experiments.

Cluster roots also formed in C. cunninghamiana root systems in these three experiments (Table 3 ) with mean numbers ranging from 2 to 57 clusters per pot in 20 of the 23 pots. The largest numbers of cluster roots were in the Niğde soil (all pots with mean of 57 per pot; a representative cluster root is shown in Figure 1d). Although, ectomycorrhizal roots developed on plants in the three soils, the numbers were again relatively low compared to A. verticillata.

\subsection{Elaeagnus angustifolia}

Elaeagnus angustifolia, the only actinorhizal species tested that is grown in Niğde, grew well and freely nodulated in Niğde soil (experiments 2 and 3) with 348 and 56 nodules per pot, respectively. The nodules range from small single-lobed nodules to multi-lobed nodules as shown in Figure 1b, c. There were two non-nodulated plants in experiment 2 . Under these conditions, $E$. angustifolia grew taller than the sheoaks but only as single stemmed plants with no development of side branches. Development of cluster roots was limited with only two examples seen in experiment 2. No ectomycorrhizal roots were found. The roots of E. angustifolia were well developed and highly branched with nodules on the main and lateral roots, but the roots were easily broken, with some browning and splitting of the cortex, so these were not scored as being as healthy as the sheoak roots in the same experiments (Table 3). In the field, E. angustifolia nodules could not be found on the shallow roots of young to mature trees, but large nodules were observed on larger roots of uprooted trees close to the main trunk (a similar situation to that described above for A. verticillata).

\section{Discussion}

A key finding is confirmation that A. glutinosa, E. angustifolia and C. cunninghamiana nodulate in Turkish soils, at least in the contexts in which the observational and experimental data were obtained. A. glutinosa and E. angustifolia nodulation was confirmed by field observation and E. angustifolia and $C$. cunninghamiana in the experiments. With C. cunninghamiana it appears that compatible Frankia might only occur in areas where it is currently grown, as nodulation did not occur in treatments without amendment with soil from such locations. The reference plant, A. verticillata, did not nodulate in any experiment, even with the suspension of conspecific nodules, which is not unexpected as Allocasuarina spp. are generally less readily nodulated than Casuarina spp. and compatible Frankia strains are less adaptable to establishment beyond their native range (Simonet et al. 1999).

The prolific nodulation of E. angustifolia seedlings grown in pots with a proportion Niğde soil contrasts starkly with the difficulty in finding nodulated plants in the field. In the uprooted mature trees examined only a few large nodules were found, so it appears that the reliance E. angustifolia has on biologically-fixed nitrogen might decline as the plant matures. Confidently quantifying the relative proportion of nitrogen acquired as biologically-fixed nitrogen in mature trees is technically challenging and requires considerable data collection over several years (Boddey et al. 2000). Nodules can be readily obtained from some mature actinorhizal trees and have been used as a source of inoculum, for example A. glutinosa (Markham and Chanway 1999) and Casuarina equisetifolia (Karthikeyan et al. 2013), for both research and production purpose. However, for the present study, efforts to find nodules on shallow roots of both $A$. verticillata in native stands and C. cunninghamiana in Turkey were unsuccessful. Nodulation in mature legumes is considered to be less common as they recycle much of their nitrogen (Sprent 2005). Bauters et al. (2016) report no detectable nodules on mature leguminous trees in late successional forest plus their seedlings and herbaceous legumes in the understory were not nodulated. Therefore, in low-productive, semiarid contexts, such as Central Anatolia, with other soil nutrient limitations, decline in nodulation as trees mature seems likely.

Cluster roots, which form in the Casuarinaceae in response to P or Fe deficiency (Arahou and Diem 1997; Reddell et al. 1997), occurred in moderate to large numbers in C. cunninghamiana, particularly in Niğde soil, a soil which causes significant $\mathrm{Fe}$ chlorosis (experiments 1 and 3 ) in this species. A low instance of structures scored as cluster roots were found in A. verticillata and E. angustifolia but given the low incidence and numbers, it is not possible to be confident that these were formed or functioning in response to a particular nutrient deficiency. Cluster roots are known to occur inconsistently in Allocasuarina (Diem et al. 2000) but have not been reported in A. verticillata or E. angustifolia, so the possibility that they can develop in these taxa deserves further investigation. 
In contrast, ectomycorrhizal roots developed in high numbers in A. verticillata from the resident mycorrhizal fungi in Turkish soil, and to a lesser extent in C. cunninghamiana. E. angustifolia did not appear to have ectomycorrhizal roots, despite being grown in soil where this species is common under conditions favourable for ectomycorrhizal root development in $C$. cunninghamiana. The Elaeagnaceae is variously reported to form both vesicular arbuscular mycorrhizal and ectomycorrhizal associations (Gardner 1986; Harley and Harley 1987; Nedelin 2014), but primary reports on ectomycorrhiza in E. angustifolia are not easily found.

In conclusion, it is likely and, as expected, that the native actinorhizal plants of Turkey will be nodulated where they occur naturally, and this has been confirmed for A. glutinosa in Rize and E. angustifolia in Niğde. The exotic $C$. cunninghamiana is likely to be nodulated where it is currently established in Turkey, but its use in new areas or the introduction of other Casuarinaceae, as has been proposed (Riley 2021), would best be accompanied with compatible Frankia inoculum. The establishment of other root structures/associations in both Allocasuarina and Casuarina adaptive for infertile soil are likely to require specific intervention, but this remains to be confirmed for vesicular arbuscular mycorrhizal associations. Also, the nodulation of status of the natives, D. cannabina and $H$. rhamnoides, remains to be investigated.

\section{Acknowledgements}

E Ekbiç (Ordu University), F Ersin (Ege University), S Serçe (Niğde Ömer Halisdemir University), JR Rathjen and MH Ryder (University of Adelaide) are gratefully acknowledged for their help in obtaining materials used in this study. Special thanks also to NF Tutar for her technical assistance with experiment 3. Authors, MA, KJ and EO, are grateful for scholarships provided by Ayhan Şahenk Foundation and KJ for the support provided by the Turkish Council of Higher Education.

\section{References}

Arahou M, Diem HG (1997) Iron deficiency induces cluster (proteoid) root formation in Casuarina glauca. Plant Soil 196: 71-79.

Batista-Santos P, Duro N, Rodrigues AP, Semedo JN, Alves P, da Costa M, Graça I, Pais IP, Scotti-Campos P, Lidon FC, Leitão AE, Pawlowski K, Ribeiro-Barros AI, Ramalho JC (2015) Is salt stress tolerance in Casuarina glauca Sieb. ex Spreng. associated with its nitrogen-fixing root-nodule symbiosis? An analysis at the photosynthetic level. Plant Physiology and Biochemistry 96: 97-109.

Bauters M, Mapenzi N, Kearsley E, Vanlauwe B, Boeckx P (2016) Facultative nitrogen fixation by legumes in the central Congo basin is downregulated during late successional stages. Biotropica 48: 281284.

Benson DR, Silvester WB (1993) Biology of Frankia strains, actinomycete symbionts of actinorhizal plants. Microbiological Reviews 57: 293-319.

Boddey RM, Peoples MB, Palmer B, Dart PJ (2000) Use of the ${ }^{15} \mathrm{~N}$ natural abundance technique to quantify biological nitrogen fixation by woody perennials. Nutrient Cycling in Agroecosystems 57: 235270.

Brundrett MC, Tedersoo L (2020) Resolving the mycorrhizal status of important northern hemisphere trees. Plant Soil 454: 3-34.

Diem HG, Duhoux E, Zaid H, Arahou M (2000) Cluster roots in Casuarinaceae: role and relationship to soil nutrient factors. Annals of Botany 85: 929-936.
Gardner IC (1986) Mycorrhizae of actinorhizal plants. MIRCEN Journal of Applied Microbiology and Biotechnology 2: 147-60.

Harley JL, Harley EL (1987) A check-list of mycorrhiza in the British flora. New Phytologist 105: 1-102.

Karthikeyan A, Chandrasekaran K, Geetha M, Kalaiselvi R (2013) Growth response of Casuarina equisetifolia Forst. rooted stem cuttings to Frankia in nursery and field conditions. Journal of Biosciences 38: 741-747.

Kier G, Mutke J, Dinerstein E, Ricketts TH, Küper W, Kreft H, Barthlott W (2005) Global patterns of plant diversity and floristic knowledge: global plant diversity. Journal of Biogeography 32: 1107-1116.

Markham JH, Chanway CP (1999) Does past contact reduce the degree of mutualism in the Alnus rubra - Frankia symbiosis? Canadian Journal of Botany 77: 434-441.

Markham JH (2009) Does Dryas integrifolia fix nitrogen? Botany 87: 1106-1109.

Nedelin T (2014) Ectomycorrhiza - nature and significance for functioning of forest ecosystems. Forestry Ideas 20: 3-29.

Parrotta JA (1999) Productivity, nutrient cycling, and succession in single- and mixed-species plantations of Casuarina equisetifolia, Eucalyptus robusta, and Leucaena leucocephala in Puerto Rico. Forest Ecology and Management 124: 45-77.

Paschke MW (1997) Actinorhizal plants in rangelands of the western United States. Journal of Range Management 50: 62-72.

Põlme S, Bahram M, Kõljalg U, Tedersoo L (2014) Global biogeography of Alnus-associated Frankia actinobacteria. New Phytologist 204: 979-988.

Reddell P, Yun Y, Shipton WA (1997) Cluster roots and mycorrhizae in Casuarina cunninghamiana: their occurrence and formation in relation to phosphorus supply. Australian Journal of Botany 45: 4145.

Riley IT (2021) A case for assessing Allocasuarina and Casuarina spp. for use in agroecosystem improvement in semi-arid areas with a focus on Central Anatolia, Turkey. Frontiers of Agricultural Science and Engineering 8: 568-582.

Riley IT, Korkmaz LN (2019) Identity of the Casuarina sp. in Turkey. Turkish Journal of Weed Science 20: 159-168.

Roy S, Khasa D, Greer C (2011) Combining alders, frankiae, and mycorrhizae for the revegetation and remediation of contaminated ecosystems. Canadian Journal of Botany 85: 237-251.

Simonet P, Navarro E, Rouvier C, Reddell P, Zimpfer J, Dommergues Y, Bardin R, Combarro P, Hamelin J, Domenach A-M, Gourbière F, Prin Y, Dawson JO, Normand P (1999) Co-evolution between Frankia populations and host plants in the family Casuarinaceae and consequent patterns of global dispersal. Environmental Microbiology 1: 525-533.

Sprent J (2005) West African legumes: the role of nodulation and nitrogen fixation. New Phytologist 167: 326-330.

Torrey JG (1976) Initiation and development of root nodules of Casuarina (Casuarinaceae). American Journal of Botany 63: 335344.

Tukey JW (1997) Exploratory Data Analysis. Addison-Wesley, Reading, MA, USA. 